\title{
Improved load flow formulation for radial distribution networks
}

\author{
Norainon Mohamed ${ }^{1}$, Dahaman Ishak ${ }^{2}$ \\ ${ }^{1}$ Faculty of Electrical and Electronics Engineering, Universiti Malaysia Pahang, Malaysia \\ ${ }^{2}$ School of Electrical and Electronic Engineering, Universiti Sains Malaysia, Malaysia
}

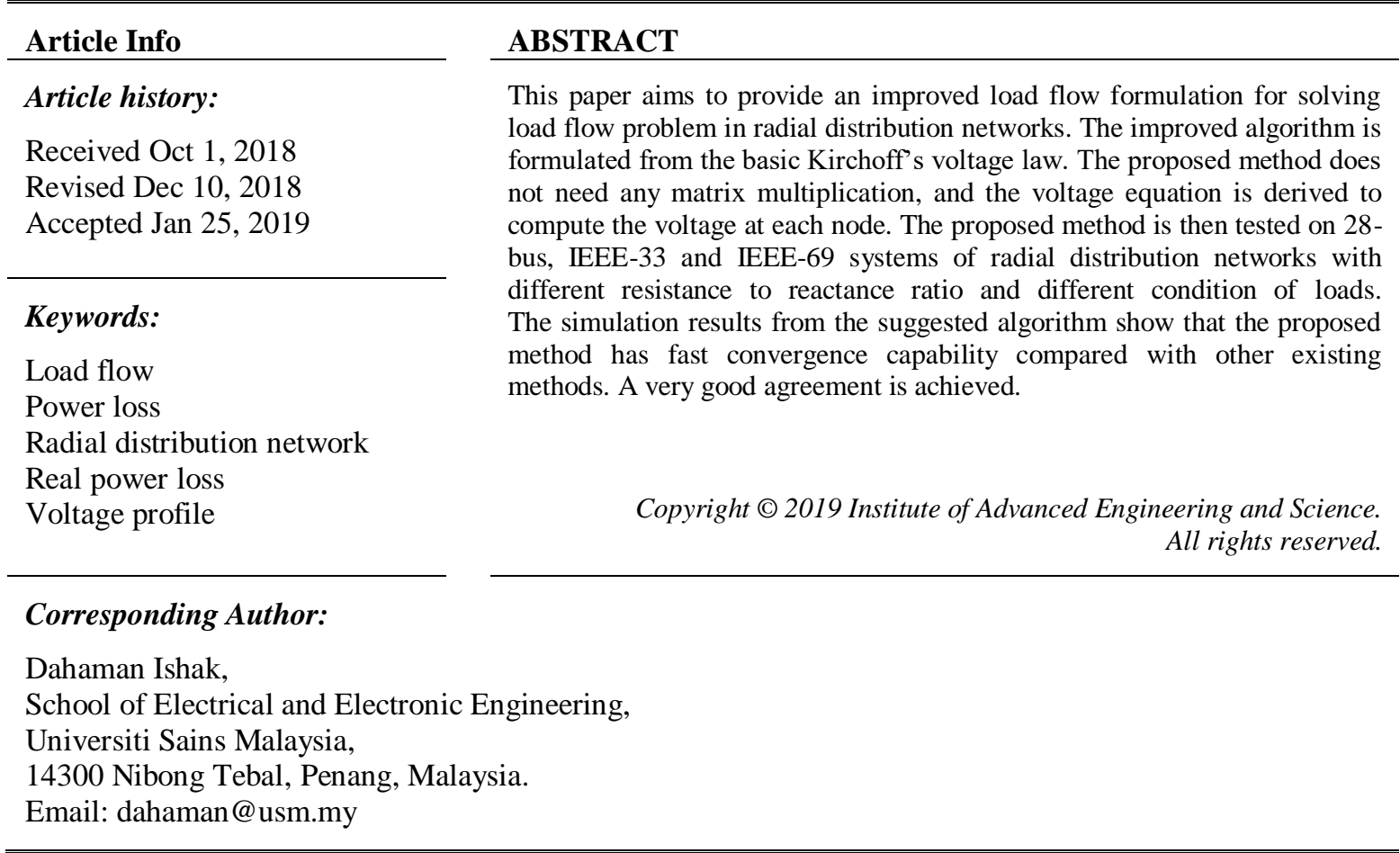

\section{INTRODUCTION}

Load flow study can be considered as an important aspect of power system planning, analysis, operation and control. It is normally used to check whether the voltage profiles are within the limits throughout the network at the design stage [1]. Additionally, the load flow study can also predict the network stability, reliability and the required protection scheme. However, the conventional Newton-Rhapson and fast decoupled load flow methods for the transmission systems often encounter convergence problem and cannot be applied for the distribution networks due to high $\mathrm{R} / \mathrm{X}$ ratio [2]. For the load flow analysis to be acceptable, it should meet the conditions for low storage requirement, high speed, high reliability, accepted versatility and simplicity [3]. Therefore, many researchers have attempted to propose modified versions of conventional power flow related to the distribution networks.

For instance, researchers in $[4,5]$ proposed load flow solution to calculate the voltage magnitudes but did not mention any procedures to estimate the voltage phase angles. In [6], the authors implemented the load flow solution for radial and meshed distribution networks by using matrix multiplication. Another load flow method using dynamic data matrix for radial distribution systems was provided in [7]. However, the proposed method depends on the system's topology and converged after more than twenty iterations. A novel matrix transformation technique was developed in [8], which directly solves the determinants of branch flows in the radial distribution networks, consequently it makes forward and backward sweeps based on load flow method. Another load flow analysis hybridized with PV nodes and backward/forward sweep was presented in [9]. A novel of load flow algotirhm was proposed by the authors in [10] for calculating the distribution grid systems. Researchers in [11] implemented the traditional load flow method in distribution networks, but the method was not useful for active distribution system networks and the load was modelled 
using heuristic method. Another method called multi-agent communication system was proposed by the authors in [12] in order to solve for unbalanced radial distribution networks. In [13], a load flow approach for radial distribution system was developed using different static of loads. Cholesky factorization method was used for the load flow analysis by modelling the loads and wind power as probability functions in [14]. A technique called breadth first search (BFS) method was developed to integrate with backward/forward sweep technique for solving the distribution networks in [15].

However, this paper aims to improve the existing load flow studies aforementioned, to fill the research gaps of longer execution time, high computational burden, complicated coding scheme to identify the branches and nodes by providing a simplified method to evaluate the voltage magnitude and its phase angle, the real and reactive power losses under influence of diferent $\mathrm{R} / \mathrm{X}$ ratios and different load conditions. The improved load flow formulation is then tested on standard distribution systems, and the simulation results are compared with other existing methods.

\section{ASSUMPTIONS}

In order to implement the improved load flow formulation, it is assumed that the three-phase systems are balanced and the charging capacitance is neglected

\section{PROBLEM FORMULATIONS}

A single-line diagram of a balanced three-phase supply in radial distribution system is shown in Figure 1. The notation $i$ represents the node number or bus number. The voltage at bus $i$ is represented as $V_{i}$, voltage at bus $(i+1)$ is $\mathrm{V}_{i+1}$, impedance of the line, $Z_{i}$, and the load current represent as $I_{i}$. The load current can be calculated as (1) where $S_{i}$ is the complex load at node $i$.

$$
I_{i}=\left(\frac{S_{i}}{V_{i}}\right)^{*}=\left(\frac{P_{i}+j Q_{i}}{V_{i}}\right)^{*}
$$

The line current can also be estimated as

$$
I_{(i, i+1)}=I_{(i+1)}+\sum \text { current emanating from node } i+1
$$

By applying the Kirchoff's voltage law (KVL) at node $i$, the voltage at node $i$ can be calculated as

$$
V_{i}=V_{i+1}+I_{(i, i+1)} \cdot Z_{i}
$$

Knowing the line current, the real and reactive power losses can be determined as

$$
\begin{aligned}
& P_{(i, i+1)}=I_{(i, i+1)}^{2} \cdot R_{i} \\
& Q_{(i, i+1)}=I_{(i, i+1)}^{2} \cdot X_{i}
\end{aligned}
$$

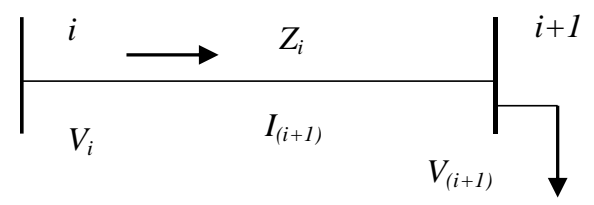

Figure 1. Single-line diagram for balanced power system network.

\subsection{Power Flow in the Improved Load Flow Formulation}

The voltage magnitudes, phase angles, real and reactive power losses for radial distribution networks can be obtained from the following steps: 
Step 1: Read the line and the load data.

Step 2: Initialize the base values for MVA and $\mathrm{kV}$.

Step 3: Calculate the base impedance and convert the line and load parameters into per unit (p.u) value.

Step 4: Construct the incidence matrix [16] to identify the branches and nodes. The positive value of 1 indicate the sending end of the branch $i$, negative value of 1 will be the receiving end of the branch $i$, and 0 if there is no connection between the nodes. The incidence matrix for the branch to node is

$$
I M=\left[\begin{array}{cccccccc}
1 & 0 & 0 & 0 & 0 & 0 & 0 & 0 \\
1 & 1 & 0 & 0 & 0 & 0 & 0 & 0 \\
0 & -1 & 1 & 0 & 0 & 0 & 0 & 0 \\
0 & 0 & -1 & 1 & 0 & 0 & 0 & 0 \\
0 & -1 & 0 & 0 & 1 & 0 & 0 & 0 \\
0 & 0 & 0 & 0 & -1 & 1 & 0 & 0 \\
0 & 0 & -1 & 0 & 0 & 0 & 1 & 0 \\
0 & 0 & 0 & 0 & 0 & 0 & -1 & 1
\end{array}\right]
$$

Step 5: Construct the node to branch which is the inverse incidence matrix [16].

Step 6: Find the end of each node of the bus system, calculate the total end nodes, lateral and sub-lateral of the bus system, and link them to calculate the current and voltage.

For example, from the sample power system network as shown in Figure 2, the end of the nodes are node 4, 6 and 8 . Therefore, the total number of end nodes are 3 . The lateral (branch) of the system are 3 . The lat[1]= $1,2,3,4$; lat[2] $=2,5,6$ and lat $[3]=3,7,8$.

Step 7: Initialize the bus voltage, $\mathrm{v}(\mathrm{i})=1.0$ for all $i=1,2,3, \ldots \mathrm{n}_{\max }$, number of iteration $=0$, and tolerance $=0.0001$.

Step 8: Calculate the load current using (1) for each nodes and linked them in order to calculate the branch or line current using (2) starting from the last nodes to downstream until the substation node for each branches. This is the application of basic current law, KCL where the current injection is equal to the load current.

Step 9: Calculate the voltage at each node using (3) which is from the calculated branch currents starting from the substation nodes towards to the last nodes for each branches. Calculate the voltage mismatch between the present and previous iterations. If the error is less than 0.0001 , then the load flow calculation has converged, otherwise go to Step 8.

Step 10: Calculate the real and reactive power losses at each bus using (4) and (5). Modification has been made in order to calculate the power losses using branch currents. Therefore, real and reactive power loss can be easily determined in Step 8 and reduced CPU time.

Step 11: Calculate the total real and reactive power losses of the system, find the minimum voltage anddisplay the results.

Step 12: Stop

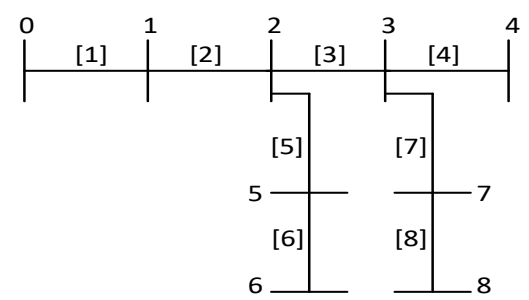

Figure 2. Sample power system network with branches and nodes

\section{SIMULATION RESULTS}

The proposed method as shown in previous section has been tested on the 28 bus, IEEE 33 and IEEE 69 bus radial distribution systems respectively in MATLAB 2017 and run on Intel's i3 processor with Windows 7 operating system and clock of $1.90 \mathrm{GHz}$. A tolerance of 0.0001 on voltage magnitude is used as a convergence criteria. The proposed algorithm is considered to successfully reach convergence if the voltage mismatch between any two successive iterations is less than or equal to 0.0001 p.u. While implementing the proposed method, it is assumed that: (a) three-phase radial distribution systems are balanced and represented 
by their single-line diagrams; (b) charging capacitance is neglected in the distribution voltage level.; (c) the load flow has been compared for constant power load modeling.

The summary of the results for the 28-bus system is shown in Table 1. The base kV and MVA are $11 \mathrm{kV}$ and $100 \mathrm{MVA}$, respectively. The bus and line data of the system can be found in Appendix. Table 1 gives the line number, the voltage magnitude and its phase angle at the receiving ends. From Table 1 , total real and reactive power losses are $68.72 \mathrm{~kW}$ and $45.97 \mathrm{kVar}$, respectively. These are $8.28 \%$ and $8.81 \%$ of their loads. The minimum voltage is 0.9133 p.u. at bus 26 . The load flow results are verified with two previously published papers in [17-18] as given in Table 2. It is observed that the voltage profile has improved with the decreases in power losses. The total real and reactive losses are reduced, and the minimum voltage is improved in the proposed method. From Table 2, it can be noted that the results obtained from the proposed method have closely matched with that of [18].

The second test case is an IEEE-33 bus, $12.66 \mathrm{kV}, 100$ MVA, 33 nodes and 32 lines for radial distribution system. The line and load data for this system is given in Appendix. At the nominal voltage, the total real and reactive power losses are $3715 \mathrm{~kW}$ and $2300 \mathrm{kVar}$, respectively. The load flow solutions for bus voltage (in p.u) and phase angle (in rad) are tabulated in Table 3. From the results, the real and reactive power losses at bus 18 are $210.0628 \mathrm{~kW}$ and $142.5248 \mathrm{kVar}$ or $5.65 \%$ and $6.2 \%$ of their nominal losses respectively. The minimum voltage occurs at bus 18 with 0.9042 p.u. These results are also compared with other methods for the real and reactive power losses and the minimum voltage at which bus it occurs as illustrated in Table 4. From this comparison, it can also be observed that the magnitudes of the voltage are almost equal. The proposed method has computed for almost the same voltage magnitudes with the convergence rate of 0.0001 . Authors in $[2,6,16,19,21-23]$ obtained the real power losses for the base case were different from the authors in [3, 20]. This happens because the researchers in $[2,6,16,19,21-23]$ have chosen the values for resistance and reactance at $7^{\text {th }}$ line data as $1.7114 \Omega$ and $1.2351 \Omega$ respectively. Whereas for $[3,20]$, both resistance and reactance were taken to be $0.7114 \Omega$ and $0.2351 \Omega$ respectively.

Table 1. Voltage and Phase Angles from Simulation Results for 28-bus Radial Distribution Networks

\begin{tabular}{ccccccc}
\hline \multicolumn{6}{c}{ Convergence rate 10 $^{-4}$} \\
\hline Node & $\mathbf{V}(\mathbf{p . u})$ & $\boldsymbol{\delta}(\boldsymbol{r a d})$ & Node & $\mathbf{V}(\mathbf{p . u})$ & $\boldsymbol{\delta}(\mathbf{r a d})$ \\
\hline 1 & 1.0000000 & 0.0000000 & 15 & 0.9432998 & 0.0152452 \\
2 & 0.9863163 & 0.0029824 & 16 & 0.9375553 & 0.0146665 \\
3 & 0.9666978 & 0.0074175 & 17 & 0.9264808 & 0.0176244 \\
4 & 0.9527096 & 0.0106982 & 18 & 0.9255211 & 0.0181109 \\
5 & 0.9386695 & 0.0141202 & 19 & 0.9238817 & 0.0189454 \\
6 & 0.9282349 & 0.0167384 & 20 & 0.9230383 & 0.0193759 \\
7 & 0.9191517 & 0.0190741 & 21 & 0.9224153 & 0.0196948 \\
8 & 0.9167180 & 0.0197059 & 22 & 0.9163278 & 0.0205363 \\
9 & 0.9164404 & 0.0197783 & 23 & 0.9148220 & 0.0213206 \\
10 & 0.9161973 & 0.0198416 & 24 & 0.9136700 & 0.0219220 \\
11 & 0.9466007 & 0.0136370 & 25 & 0.9134157 & 0.0220549 \\
12 & 0.9448555 & 0.0144860 & $\mathbf{2 6}$ & $\mathbf{0 . 9 1 3 2 5 3 6}$ & $\mathbf{0 . 0 2 2 1 3 9 9}$ \\
13 & 0.9438129 & 0.0149946 & 27 & 0.9162326 & 0.0199571 \\
14 & 0.9435370 & 0.0151294 & 28 & 0.9161112 & 0.0200199 \\
\hline
\end{tabular}

Table 2. Comparison of Load Flow Results for 28-bus Radial Distribution Networks

\begin{tabular}{|c|c|c|c|c|c|c|}
\hline \multirow[b]{2}{*}{ Methods } & \multicolumn{2}{|c|}{ Power Losses } & \multirow[b]{2}{*}{$\mathbf{V}_{\min (\mathbf{p . u})}$} & \multirow[b]{2}{*}{$\begin{array}{l}\text { Bus } \\
\text { no. }\end{array}$} & \multirow[b]{2}{*}{$\begin{array}{c}\text { Convergance } \\
\text { rate }\end{array}$} & \multirow[b]{2}{*}{$\begin{array}{c}\text { Iteration } \\
\text { no. }\end{array}$} \\
\hline & $\operatorname{Real}(k W)$ & $\begin{array}{c}\text { Reactive } \\
\text { (kVar) }\end{array}$ & & & & \\
\hline Proposed Method & 68.71761 & 45.97376 & 0.9133 & 26 & $10^{-4}$ & 4 \\
\hline Peddanna and Kishore [18] & 68.84580 & 46.02310 & 0.9124 & 26 & - & - \\
\hline D.Das et., al[17] & 68.79110 & 46.06950 & 0.9127 & 26 & - & - \\
\hline
\end{tabular}

The proposed load flow was also tested for the 69-node, $12.66 \mathrm{kV}, 100 \mathrm{MVA}$ radial distribution system. The line and load data for this system are available in [5]. The total real and reactive power loads consumed at nominal voltage are $3791.89 \mathrm{~kW}$ and $2694.10 \mathrm{kVAr}$, respectively. The load flow results for bus voltages and phase angles of this system are given in Table 5. From the proposed method, the real and reactive power losses at bus 65 are $224.8721 \mathrm{~kW}$ and $102.1535 \mathrm{kVAr}$ or $5.93 \%$ and $3.79 \%$ of their respective real and reactive loads. The minimum voltage of the system is 0.910152 at bus 65 . The proposed algorithm has been verified with other eight existing methods for constant power load as presented in Table 6 . The real and reactive power losses, minimum voltage, convergence rate corresponding to the number of iterations are 
shown in Table 6. From this table, the results from the proposed load flow technique have agreed very well with those presented in [18].

Table 3. Voltage and phase angle from simulation results for IEEE-33 bus radial distribution networks.

\begin{tabular}{cccccc}
\hline \multicolumn{6}{c}{ Convergence rate 10 } \\
\hline Node & V(p.u) & $\boldsymbol{\delta}($ rad $)$ & Node & V(p.u) & $\boldsymbol{\delta}($ rad $)$ \\
\hline 0 & 0.000000 & 0.000000 & 17 & 0.904819 & -0.01281 \\
1 & 1.000000 & 0.000000 & $\mathbf{1 8}$ & $\mathbf{0 . 9 0 4 2 1 1}$ & $\mathbf{- 0 . 0 1 3 0 0}$ \\
2 & 0.997021 & 0.000239 & 19 & 0.996493 & 0.00005 \\
3 & 0.982924 & 0.001682 & 20 & 0.992919 & -0.00113 \\
4 & 0.975441 & 0.002845 & 21 & 0.992216 & -0.00147 \\
5 & 0.968042 & 0.004024 & 22 & 0.991580 & -0.00183 \\
6 & 0.949627 & 0.002412 & 23 & 0.979339 & 0.001137 \\
7 & 0.946158 & -0.001680 & 24 & 0.972671 & -0.000420 \\
8 & 0.932554 & -0.004600 & 25 & 0.969348 & -0.001190 \\
9 & 0.926249 & -0.006030 & 26 & 0.947710 & 0.003130 \\
10 & 0.920400 & -0.007260 & 27 & 0.945164 & 0.004152 \\
11 & 0.919530 & -0.007160 & 28 & 0.933758 & 0.005794 \\
12 & 0.918012 & -0.00699 & 29 & 0.925569 & 0.007298 \\
13 & 0.911875 & -0.00876 & 30 & 0.922043 & 0.009199 \\
14 & 0.909616 & -0.01021 & 31 & 0.917863 & 0.007794 \\
15 & 0.908205 & -0.01092 & 32 & 0.916942 & 0.007407 \\
16 & 0.906834 & -0.01137 & 33 & 0.916657 & 0.007276 \\
\hline
\end{tabular}

Table 4. Comparison of Load Flow Results for IEEE-33 bus Radial Distribution Networks

\begin{tabular}{|c|c|c|c|c|c|c|}
\hline \multirow[b]{2}{*}{ Methods } & \multicolumn{2}{|c|}{ Power Losses } & \multirow[b]{2}{*}{$V_{\min }(\mathbf{p . u})$} & \multirow{2}{*}{$\begin{array}{l}\text { Bus } \\
\text { no. }\end{array}$} & \multirow{2}{*}{$\begin{array}{c}\text { Convergance } \\
\text { rate }\end{array}$} & \multirow{2}{*}{$\begin{array}{c}\text { Iteration } \\
\text { no. }\end{array}$} \\
\hline & $\operatorname{Real}(k W)$ & Reactive (kVar) & & & & \\
\hline Teja et., al[19] & 210.9824 & 143.0219 & 0.903776 & 18 & $10^{-4}$ & 4 \\
\hline Babu B. and Maheswarapu [6] & 210.9800 & 143.0200 & 0.903776 & 18 & $10^{-4}$ & 4 \\
\hline Malik et., al[23] & 210.9700 & 143.1100 & 0.903000 & 18 & $10^{-4}$ & 4 \\
\hline Proposed Method & 210.0628 & 142.5248 & 0.904211 & 18 & $10^{-4}$ & 4 \\
\hline Ramana et., al[2] & 209.6800 & 142.2000 & 0.905090 & 18 & $10^{-4}$ & 2 \\
\hline Hamouda and Zehar [16] & 205.1900 & 139.2300 & 0.904100 & 18 & $10^{-4}$ & 2 \\
\hline Nagaraju et., al[3] & 202.6817 & 135.2370 & 0.913080 & 18 & $10^{-5}$ & 4 \\
\hline Vasquez and Quilumba [7] & 211.0000 & - & 0.903700 & 18 & $10^{-3}$ & 23 \\
\hline Ghosh and Sherpa [20] & 202.3000 & 135.0200 & 0.909924 & 18 & $10^{-5}$ & - \\
\hline Kumar et., al[22] & 210.9716 & 143.9716 & 0.903780 & 18 & - & - \\
\hline Rupa and Ganesh [21] & 203.6500 & 102.6000 & 0.913600 & 18 & - & - \\
\hline
\end{tabular}

The proposed algorithm was also tested for different $\mathrm{R} / \mathrm{X}$ ratios in order to investigate its effect on the voltage profile in the 28-node and IEEE-33 bus test systems as shown in Figure 3 and Figure 4, respectively. As can be observed, the increase of $\mathrm{R} / \mathrm{X}$ ratio will reduce the voltage magnitude of the system. The load voltage also varies with the different loading conditions by multiplying their real and reactive powers by a constant. The effect of different loads has been implemented for the IEEE-69 bus test system as shown in Figure 4. The p.u values of the voltage decrease with the increase in the load because the increasing branch current which leads to larger voltage drop. However, from nodes 27 to 45, the voltage magnitudes are fairly constant because these nodes are quite close to the source node with small line parameters and the loads are at low level. The proposed technique was also tested on convergence rate for the values of $10^{-1}$, $10^{-2}, 10^{-3}, 10^{-4}, 10^{-5}$ and $10^{-6}$. The results are tabulated in Table 7 . From Table 7 , it can be observed that the tolerance level decreases with the decrease of convergence rate. Table 8 shows the the comparison of relative CPU time with other existing methods for constant power load model. It can be seen that the proposed algorithm gives better CPU time compared to other existing methods, and can be concluded that the proposed method is time efficient for radial distribution system. 
Table 5. Voltage and Phase Angle from Simulation Results for IEEE-69 bus Radial Distribution Networks

\begin{tabular}{cccccc}
\hline \multicolumn{5}{c}{ Convergence rate $10^{-4}$} & \\
\hline Node & $\mathrm{V}(\mathrm{p} . \mathrm{u})$ & $\delta(\mathrm{rad})$ & Node & $\mathrm{V}(\mathrm{p} . \mathrm{u})$ & $\delta(\mathrm{rad})$ \\
\hline 0 & 0.000000 & 0.000000 & 35 & 0.998946 & 0.000184 \\
1 & 1.000000 & 0.000000 & 36 & 0.999918 & -0.000050 \\
2 & 0.999966 & -0.000021 & 37 & 0.999747 & -0.000160 \\
3 & 0.999932 & -0.000041 & 38 & 0.999588 & -0.000200 \\
4 & 0.999837 & -0.000099 & 39 & 0.999542 & -0.000220 \\
5 & 0.999012 & -0.000290 & 40 & 0.999540 & -0.000220 \\
6 & 0.990115 & 0.001166 & 41 & 0.998843 & -0.000410 \\
7 & 0.980862 & 0.002712 & 42 & 0.998550 & -0.000490 \\
8 & 0.978656 & 0.003084 & 43 & 0.998512 & -0.000500 \\
9 & 0.977528 & 0.003276 & 44 & 0.998503 & -0.000500 \\
10 & 0.972527 & 0.004823 & 45 & 0.998405 & -0.000540 \\
11 & 0.971401 & 0.005131 & 46 & 0.998405 & -0.000540 \\
12 & 0.968236 & 0.006099 & 47 & 0.999787 & -0.00013 \\
13 & 0.965298 & 0.006957 & 48 & 0.998547 & -0.00092 \\
14 & 0.962386 & 0.007810 & 49 & 0.994719 & -0.00338 \\
15 & 0.959503 & 0.008658 & 50 & 0.994177 & -0.00373 \\
16 & 0.958968 & 0.008816 & 51 & 0.978620 & 0.003090 \\
17 & 0.958082 & 0.009077 & 52 & 0.978611 & 0.003093 \\
18 & 0.958073 & 0.009079 & 53 & 0.974762 & 0.003779 \\
19 & 0.957602 & 0.009235 & 54 & 0.971544 & 0.004366 \\
20 & 0.957300 & 0.009335 & 55 & 0.967105 & 0.005185 \\
21 & 0.956811 & 0.009497 & 56 & 0.962771 & 0.005992 \\
22 & 0.956805 & 0.009499 & 57 & 0.940635 & 0.013943 \\
23 & 0.956733 & 0.009524 & 58 & 0.929747 & 0.018002 \\
24 & 0.956578 & 0.009578 & 59 & 0.925538 & 0.019621 \\
25 & 0.956406 & 0.009631 & 60 & 0.920602 & 0.021691 \\
26 & 0.956337 & 0.009655 & 61 & 0.913275 & 0.023264 \\
27 & 0.956317 & 0.009662 & 62 & 0.912988 & 0.023326 \\
28 & 0.999925 & -0.000005 & 63 & 0.912604 & 0.023410 \\
29 & 0.999854 & -0.000091 & 64 & 0.910721 & 0.023819 \\
30 & 0.999732 & -0.000054 & $\mathbf{6 5}$ & $\mathbf{0 . 9 1 0 1 5 2}$ & $\mathbf{0 . 0 2 3 9 4 3}$ \\
31 & 0.999711 & -0.000048 & 66 & 0.971345 & 0.005152 \\
32 & 0.999604 & -0.000015 & 67 & 0.971344 & 0.005152 \\
33 & 0.999348 & 0.000063 & 68 & 0.967907 & 0.006209 \\
34 & 0.999013 & 0.000165 & 69 & 0.967906 & 0.006210 \\
\hline & & & & &
\end{tabular}

Table 6. Comparison of Load Flow Results for IEEE-69 bus Radial Distribution System

\begin{tabular}{|c|c|c|c|c|c|c|}
\hline \multicolumn{4}{|c|}{ Power Losses } & \multirow[b]{2}{*}{$\begin{array}{l}\text { Bus } \\
\text { no. }\end{array}$} & \multirow[b]{2}{*}{$\begin{array}{c}\text { Convergance } \\
\text { rate }\end{array}$} & \multirow[b]{2}{*}{$\begin{array}{c}\text { Iteration } \\
\text { no. }\end{array}$} \\
\hline Methods & $\operatorname{Real}(k W)$ & Reactive (kVar) & $\mathrm{V}_{\min (\mathrm{p} . \mathrm{u})}$ & & & \\
\hline Proposed Method & 224.8721 & 102.1535 & 0.9102 & 65 & $10^{-4}$ & 4 \\
\hline Teja et., al[19] & 317.9070 & 143.8350 & 0.8754 & 65 & $10^{-4}$ & 5 \\
\hline Babu B and Maheswarapu [6] & 224.9300 & 102.1300 & 0.9038 & 65 & $10^{-4}$ & 4 \\
\hline Nagaraju et., al[3] & 224.6300 & 101.9900 & 0.9092 & 65 & $10^{-5}$ & 4 \\
\hline Hamouda and Zehar [12] & 218.8400 & 95.59000 & 0.9095 & 65 & $10^{-4}$ & 4 \\
\hline Ramana et., al[2] & 223.3100 & 101.3800 & 0.9106 & 65 & $10^{-4}$ & 2 \\
\hline Ghosh and Sherpa [20] & 225.0000 & 102.0950 & 0.9068 & 65 & $10^{-5}$ & - \\
\hline Kumar et., al[22] & 224.8011 & 102.0954 & 0.9092 & 65 & - & - \\
\hline Peddanna and Kishore [18] & 224.8799 & 102.1091 & 0.9093 & 65 & - & - \\
\hline
\end{tabular}

Table 7. Summary of Convergence Rate and Tolerance Level of the Proposed Method

\begin{tabular}{cccc}
\hline $\begin{array}{c}\text { Convergence } \\
\text { rate }\end{array}$ & 28-bus & IEEE 33-bus & IEEE 69-bus \\
\hline $10^{-1}$ & 0.080537 & 0.080340 & 0.082969 \\
$10^{-2}$ & 0.005775 & 0.005777 & 0.006993 \\
$10^{-3}$ & 0.000408 & 0.000392 & 0.000580 \\
$10^{-4}$ & 0.000026 & 0.000015 & 0.000042 \\
$10^{-5}$ & 0.000001 & 0.000002 & 0.000004 \\
$10^{-6}$ & 0.000000 & 0.000000 & 0.000000 \\
\hline
\end{tabular}




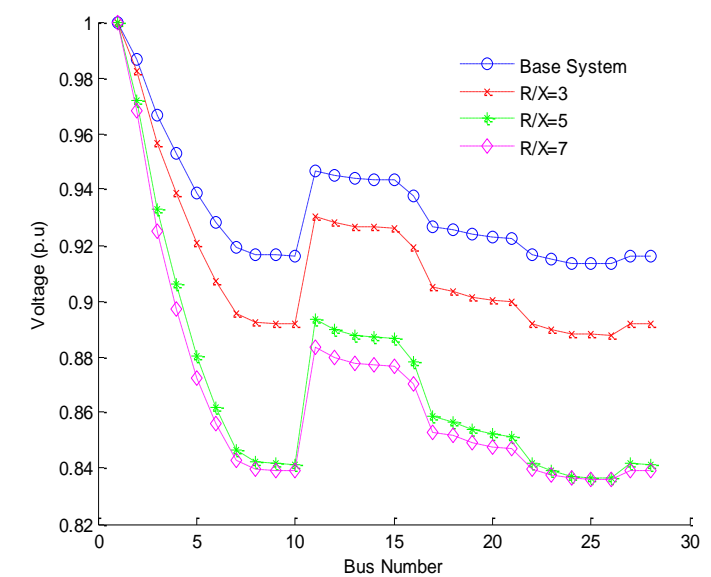

(a)

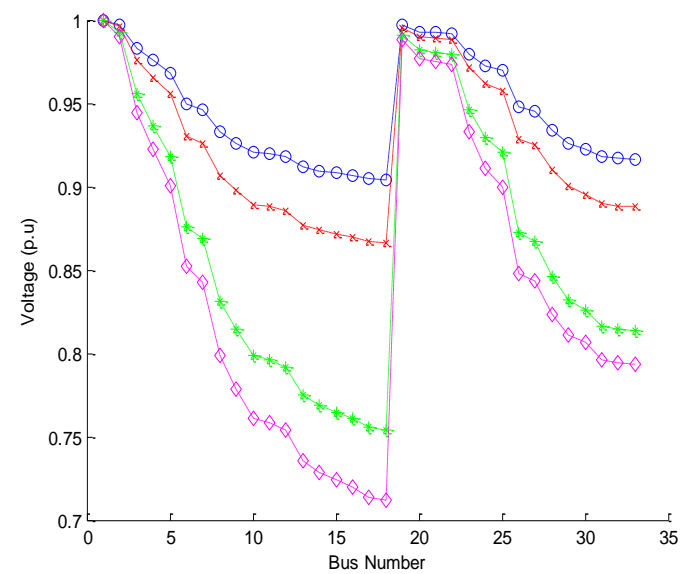

(b)

Figure 3. Voltage profile of (a) 28-bus and (b) IEEE-33 bus radial distribution system for different R/X ratio

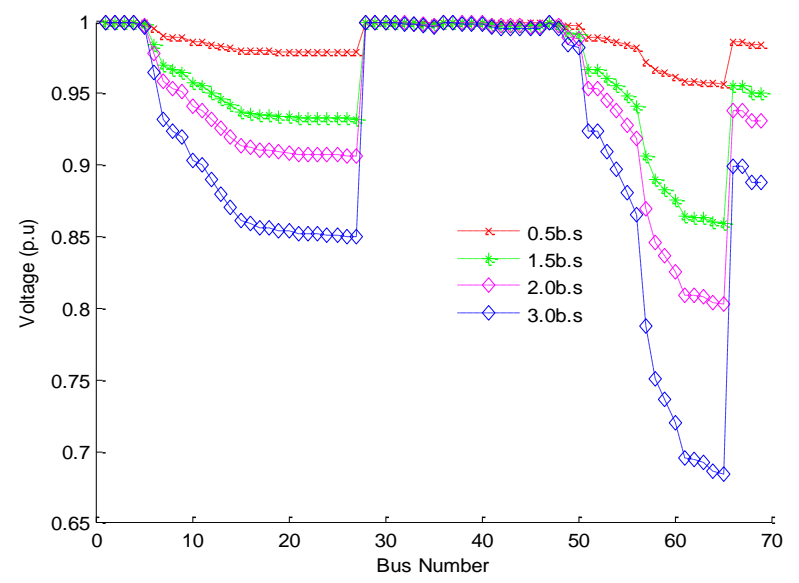

Figure 4. Effect of different loading conditions for IEEE-69 bus test system

Table 8. Comparison of CPU Time and Tolerance Level of the Proposed Method

\begin{tabular}{cccccc}
\hline \multirow{2}{*}{ Distribution } & Proposed & Satyanarayana & Singh \& Ghosh & Singh \& Ghose & Bhullar\& \\
Systems & Method & et., al.[24] & {$[25]$} & {$[8]$} & Ghosh[13] \\
\hline 28-bus & $0.89(0.080537)$ & $1.43(0.080590)$ & $1.37(0.080593)$ & $1.51(0.080658)$ & $1(0.080540)$ \\
IEEE-33 & $0.95(0.080340)$ & $1.51(0.080375)$ & $1.43(0.080368)$ & $1.57(0.080391)$ & $1(0.080348)$ \\
IEEE-69 & $0.98(0.082969)$ & $1.83(0.083011)$ & $1.71(0.082988)$ & $1.92(0.083029)$ & $1(0.082973)$ \\
\hline
\end{tabular}

\section{CONCLUSION}

In this paper, the improved load flow formulation for radial distribution network has been proposed and tested on the 28 bus, IEEE 33 and IEEE 69 bus radial distribution systems under different load conditions and different $\mathrm{R} / \mathrm{X}$ ratio. The results have been compared with the existing methods as proposed by previous researchers. From this evaluation and analysis, it is found that the proposed method can confidently be applied for the radial distribution system with good accuracy and fast convergence rate.

\section{ACKNOWLEDGEMENTS}

The authors gratefully acknowledge Universiti Sains Malaysia and Universiti Malaysia Pahang for providing technical and financial support in conducting this research and also to thank the reviewers for their comments and recommendations for improving the quality of the paper. 


\section{REFERENCES}

[1] A. D. Rana, J. B. Darji, Mosam Pandya, "Backward/Forward Sweep Load Flow Algorithm for Radial Distribution System", International Journal of Scientific Research and Development, vol. 2(01), pp. 398-400, 2014.

[2] T. Ramana, V. Ganesh, S. Sivanagaraju, "Simple and Fast Load Flow Solution for Electrical Power Distribution Systems", International Journal of Electrical Engineering and Informatics, vol. 5, pp. 245-255, Sept 2013.

[3] K. Nagaraju, S. Sivanagaraju, T. Ramana, P. V. Prasad, "A Novel Load Flow Method for Radial Distribution Systems for Realistic Loads", Electric Power Components and Systems, vol. 39, pp. 128-141, 2011.

[4] D. Das, D. P. Kothari, and A. Kalam, "Simple and Efficient Method for Load Flow Solution of Radial Distribution Networks", Elect. Power Energy Syst, vol. 17(5), pp. 335-346, 1995.

[5] R. Ranjan and D. Das, "Simple and Efficient Computer Algorithm to Solve Radial Distribution Networks", Electric Power Components and Systems, vol. 31(1), pp. 95-107, 2003.

[6] Kiran Babu B. and Sydulu Maheswarapu, "An Efficient Power Flow Method for Radial Distribution System Studies under Various Load Models", Electric Power Components and Systems, vol. 16, pp. 1-6, 2016.

[7] Wilson A. Vasquez and Franklin L. Quilumba, "Load Flow Method for Radial Distribution Systems with Distributed Generation using a Dynamic Data Matrix", Electric Power Components and Systems, vol. 16, pp. 1-6, 2016.

[8] S. Singh and T. Ghose, "Improved Radial Load Flow Method", Electric Power Components and Systems, vol. 44, pp. 721-727, 2013.

[9] Yuntao, J.u, Wenchun, W.u, Bomim, Zhang Z. \& Hongbin, Sun S., "Loop Analysis Based Continous Power Flow Algorithm for Distribution Networks", IET Generation, Transmission and Distribution, vol.8(7), pp.1284-1292, 2014.

[10] Eltantawy, A.B. \& Salama, M.M.A., "A Novel Zooming Algorithm for Distribution Load Flow Analysis for Smart Grid", IEEE Transaction of Smart Grids, vol. 5(4), pp. 1701-1711, 2014.

[11] Nikmehr, N., and Najafi Ravadanegh, "Heuristic Probabilistic Power Flow Algorithm for Microgrids Operation and Planning", IET Generation, Transmission and Distribution, vol.8(11), pp.985-995, 2015.

[12] Nguyen, C.P. \& Flueck, A.J., "A Novel Agent Based Distributed Power Flow Solver for Smart Grids", IEEE Transaction of Smart Grids, vol. 6(3), pp. 1261-1270, 2015.

[13] Suman Bhullar \& Smarajit Ghosh, "A Novel Search Technique to Solve Load Flow of Distribution Networks", Journal of Engineering Research, vol. 5(4), pp. 60-75, 2017.

[14] Narayan, K.S \& Kumar, A., "Impact of Wind Correlation and Load Correlation on Probabilistic Load Flow for Radial Distribution Systems", IEEE International Conference on Signal Processing, Informatics, Communication and Energy Systems, Kozhikode(Kerala), pp. 1-5, 2015.

[15] S. Sunisith, K. Meena, "Backward/Forward Sweep Based Distribution Load Flow Method", International Electrical Engineering Journal, vol. 5(9), pp. 1539-1544, 2014.

[16] Abdellatif Hamouda and Khaled Zehar, "Improved Algorithm for Radial Distribution Networks Load Flow Solution", Electric Power and Energy Systems, vol. 33, pp. 508-514, 2011.

[17] D. Das, D. P. Kothari, and H. S. Nagi, "Novel Method for Solving Radial Distribution Networks", IEEE Proc Gener. Transm. Distrib., vol. 141(4), pp. 291-298, 1994.

[18] Gundugallu Peddana and Y. Siva Rama Kishore, "Power Loss Allocation of Balanced Radial Distribution Systems", International Journal of Science and Research, vol. 4(9), pp. 360-366, September 2015.

[19] B. Ravi Teja, V. V. S. N. Murty, Ashwani Kumar, "An Efficient and Simple Load Flow Approach for Radial and Meshed Distribution Networks", International Journal of Grid Distributed Computing, vol. 9(2), pp. 85-201, 2016.

[20] Smarjit Ghosh and Karma Sonam Sherpa, "An Efficient Method for Load-Flow Solution of Radial Distribution Networks", World Academy of Scince, Engineering and Technology, vol. 21, pp. 700-708, 2008.

[21] J. A. Michline Rupa and S. Ganesh, "Power Flow Analysis for Radial Distribution System using Backward/Forward Sweep Method", International Journal of Electrical and Computing Engineering (IJECE), vol. 8(10), pp. 1621-1625, 2014.

[22] V.Kumar, Shubham Swapnil, R. Ranjan and V. R. Singh, "Improved Algorithm for Load Flow Analysis of Radial Distribution System", Indian Journal of Science and Technology, vol. 10(18), pp. 1-7, May 2017.

[23] Nitin Malik, Shubham Swapnil, Jaimin D.Shah, Vaibhav A. Maheshwari, "Simple Robust Power Flow Method for Radial Distribution Systems", Journal of Information, Knowledge and Research in Electrical Engineering, vol. 3(01), pp. 412-417, 2014.

[24] Satyanarayana, S.Ramana, T.,Sivanagaraju, S., \& Rao, G.K., "An Efficient Load Flow Solution for Radial Distribution Network Including Voltage Dependent Load Models", Electric Power Components and Systems, vol. 35(5), pp. 539-551, 2007.

[25] Singh, Kultar Deep \& Ghosh, T., "A New Efficient Method for Load Flow Solution for Radial Distribution Networks", Electrical Review: Engineering and Technology, pp. 66-73, 2011Eltantawy, A.B. \& Salama, M.M.A., "A Novel Zooming Algorithm for Distribution Load Flow Analysis for Smart Grid", IEEE Transaction of Smart Grids, vol. 5(4), pp. 1701-1711, 2014. 


\section{BIOGRAPHIES OF AUTHORS}
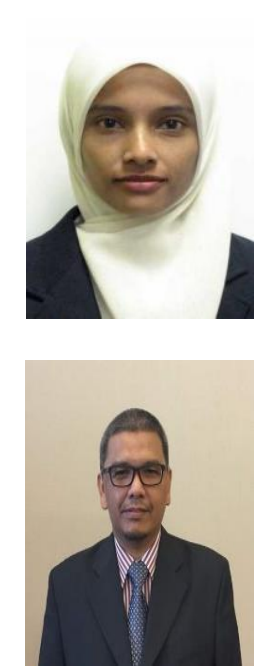

Norainon Mohamed received the B.Eng degree in Industrial Electronics from Universiti Malaysia Perlis, Malaysia in 2008 and Master Degree in Electrical Engineering from Universiti Malaysia Pahang in 2010. She is currently pursuing the $\mathrm{PhD}$ degree with the School of Electrical and Electronic Engineering, Universiti Sains Malaysia, Penang, Malaysia. Her current research area includes power system analysis, distribution and transmission systems and renewable energy resources.

Dahaman Ishak received the BSc degree in electrical engineering from Syracuse University, Syracuse, NY, USA, the MSc degree in electrical power from the University of Newcastle Upon Tyne, Newcastle upon Tyne, UK, and the $\mathrm{PhD}$ degree in electrical engineering from the University of Sheffield, Sheffield, UK, in 1990, 2001 and 2005 respectively. He is currently an Associate Professor with the School of Electrical and Electronic Engineering, Universiti Sains Malaysia, Penang, Malaysia. His current research interests include permanent magnet brushless machines, electrical drives, power electronic converters and renewable energy.s

\section{APPENDIX A}

Table A1: 28-bus radial distribution systems

\begin{tabular}{|ccccc|}
\hline $\begin{array}{c}\text { Branch } \\
\text { no. }\end{array}$ & $\begin{array}{c}\text { Sending } \\
\text { Bus }\end{array}$ & $\begin{array}{c}\text { Receiving } \\
\text { Bus }\end{array}$ & $\begin{array}{c}\mathbf{R} \\
\text { (ohms) }\end{array}$ & $\begin{array}{c}\mathbf{X} \\
\text { (ohms) }\end{array}$ \\
\hline 1 & 1 & 2 & 1.197 & 0.820 \\
2 & 2 & 3 & 1.796 & 1.231 \\
3 & 3 & 4 & 1.306 & 0.896 \\
4 & 4 & 5 & 1.851 & 1.268 \\
5 & 5 & 6 & 1.524 & 1.044 \\
6 & 6 & 7 & 1.905 & 1.305 \\
7 & 7 & 8 & 1.197 & 0.820 \\
8 & 8 & 9 & 0.653 & 0.447 \\
9 & 9 & 10 & 1.143 & 0.783 \\
10 & 4 & 11 & 2.823 & 1.172 \\
11 & 11 & 12 & 1.184 & 0.491 \\
12 & 12 & 13 & 1.002 & 0.416 \\
13 & 13 & 14 & 0.455 & 0.189 \\
14 & 14 & 15 & 0.546 & 0.227 \\
15 & 5 & 16 & 2.550 & 1.058 \\
16 & 6 & 17 & 1.366 & 0.567 \\
17 & 17 & 18 & 0.819 & 0.340 \\
18 & 18 & 19 & 1.548 & 0.642 \\
19 & 19 & 20 & 1.366 & 0.567 \\
20 & 20 & 21 & 3.552 & 1.474 \\
21 & 7 & 22 & 1.548 & 0.642 \\
22 & 22 & 23 & 1.092 & 0.453 \\
23 & 23 & 24 & 0.910 & 0.378 \\
24 & 24 & 25 & 0.455 & 0.189 \\
25 & 25 & 26 & 0.364 & 0.151 \\
26 & 8 & 27 & 0.546 & 0.226 \\
27 & 27 & 28 & 0.273 & 0.113 \\
\hline
\end{tabular}

\begin{tabular}{|llll|}
\hline $\begin{array}{l}\text { Node } \\
\text { No. }\end{array}$ & PL(kW) & $\begin{array}{l}\text { Node } \\
\text { No. }\end{array}$ & PL(kW) \\
\hline 1 & 0.000 & 15 & 35.28 \\
2 & 35.28 & 16 & 35.28 \\
3 & 14.00 & 17 & 8.960 \\
4 & 35.28 & 18 & 8.960 \\
5 & 14.00 & 19 & 35.28 \\
6 & 35.28 & 20 & 35.28 \\
7 & 35.28 & 21 & 14.00 \\
8 & 35.28 & 22 & 35.28 \\
9 & 14.00 & 23 & 8.960 \\
10 & 14.00 & 24 & 56.00 \\
11 & 56.00 & 25 & 8.960 \\
12 & 35.28 & 26 & 35.28 \\
13 & 35.28 & 27 & 35.28 \\
14 & 14.00 & 28 & 35.28 \\
\hline
\end{tabular}

Power factor of the load is taken as $\cos \phi=0.70$

Reactive power load $=$ PL $\tan \phi$

Table A2: IEEE-33 bus radial distribution systems 


\begin{tabular}{|c|c|c|c|c|c|c|}
\hline $\begin{array}{c}\text { Branch } \\
\text { no. }\end{array}$ & $\begin{array}{c}\text { Sending } \\
\text { Bus }\end{array}$ & $\begin{array}{c}\text { Receiving } \\
\text { Bus }\end{array}$ & $\begin{array}{c}\mathbf{R} \\
\text { (ohms) }\end{array}$ & $\begin{array}{c}\mathbf{X} \\
\text { (ohms) }\end{array}$ & $\begin{array}{c}\mathbf{P}_{\mathbf{L}} \\
(\mathbf{k W})\end{array}$ & $\begin{array}{c}\mathbf{Q}_{\mathrm{L}} \\
(\mathbf{k V a r})\end{array}$ \\
\hline 1 & 1 & 2 & 0.0922 & 0.0477 & 100.0 & 60.00 \\
\hline 2 & 2 & 3 & 0.4930 & 0.2511 & 90.00 & 40.00 \\
\hline 3 & 3 & 4 & 0.3660 & 0.1864 & 120.0 & 80.00 \\
\hline 4 & 4 & 5 & 0.3811 & 0.1941 & 60.00 & 30.00 \\
\hline 5 & 5 & 6 & 0.8190 & 0.7070 & 60.00 & 20.00 \\
\hline 6 & 6 & 7 & 0.1872 & 0.6188 & 200.0 & 100.0 \\
\hline 7 & 7 & 8 & 1.7114 & 1.2351 & 200.0 & 100.0 \\
\hline 8 & 8 & 9 & 1.0300 & 0.7400 & 60.00 & 20.00 \\
\hline 9 & 9 & 10 & 1.0400 & 0.7400 & 60.00 & 20.00 \\
\hline 10 & 10 & 11 & 0.1966 & 0.0650 & 45.00 & 30.00 \\
\hline 11 & 11 & 12 & 0.3744 & 0.1238 & 60.00 & 35.00 \\
\hline 12 & 12 & 13 & 1.4680 & 1.1550 & 60.00 & 35.00 \\
\hline 13 & 13 & 14 & 0.5416 & 0.7129 & 120.0 & 80.00 \\
\hline 14 & 14 & 15 & 0.5910 & 0.6560 & 60.00 & 10.00 \\
\hline 15 & 15 & 16 & 0.7463 & 0.5450 & 60.00 & 20.00 \\
\hline 16 & 16 & 17 & 1.2890 & 1.7210 & 60.00 & 20.00 \\
\hline 17 & 17 & 18 & 0.7320 & 0.5740 & 90.00 & 40.00 \\
\hline 18 & 18 & 19 & 0.1640 & 0.1565 & 90.00 & 40.00 \\
\hline 19 & 19 & 20 & 1.5042 & 1.3554 & 90.00 & 40.00 \\
\hline 20 & 20 & 21 & 0.4095 & 0.4784 & 90.00 & 40.00 \\
\hline 21 & 21 & 22 & 0.7089 & 0.9373 & 90.00 & 40.00 \\
\hline 22 & 3 & 23 & 0.4512 & 0.3083 & 90.00 & 50.00 \\
\hline 23 & 23 & 24 & 0.8980 & 0.7091 & 420.0 & 200.0 \\
\hline 24 & 24 & 25 & 0.8960 & 0.7011 & 420.0 & 200.0 \\
\hline 25 & 6 & 26 & 0.2030 & 0.1034 & 60.00 & 25.00 \\
\hline 26 & 26 & 27 & 0.2842 & 0.1447 & 60.00 & 25.00 \\
\hline 27 & 27 & 28 & 1.0590 & 0.9337 & 60.00 & 20.00 \\
\hline 28 & 28 & 29 & 0.8042 & 0.7006 & 120.0 & 70.00 \\
\hline 29 & 29 & 30 & 0.5075 & 0.2585 & 200.0 & 600.0 \\
\hline 30 & 30 & 31 & 0.9744 & 0.9630 & 150.0 & 70.00 \\
\hline 31 & 31 & 32 & 0.3105 & 0.3619 & 210.0 & 100.0 \\
\hline 32 & 32 & 33 & 0.3410 & 0.5302 & 60.00 & 40.00 \\
\hline
\end{tabular}

